Seção Temática: Os Recursos Públicos em Disputa

Volume 11 - $2021 \mid$ n. 23

\title{
Análise das Relações entre os Setores Público e Privado na Educação Superior no Âmbito do Fies
}

\author{
Rodrigo Meleu das Neves \\ Universidade Federal do Rio Grande do Sul (UFRGS), Porto Alegre/RS - Brasil \\ Denise Lindstrom Bandeira \\ Universidade Federal do Rio Grande do Sul (UFRGS), Porto Alegre/RS - Brasil
}

\section{Resumo}

O Fundo de Financiamento Estudantil (Fies), criado em 1999, já financiou mais de três milhões de estudantes. O objetivo deste artigo é analisar como o Fies contribuiu para a expansão da educação superior privada no Brasil. O método utilizado foi o misto, com ênfase no modelo da estratégia explanatória sequencial, e, na perspectiva teórico-contextual, o texto representa - Fies no marco de ideias neoliberais para a ação do Estado na educação, em que a privatização e a mercantilização da educação superior são alavancadas. São examinados dados das despesas públicas com o Programa e do seu atendimento, abrangendo números de contratos, de estudantes, de instituições e da distribuição territorial. O interstício 1999-2020 registra importante aumento do acesso à educação superior e o Fies, iniciado timidamente, expandiu-se significativamente entre 2011 e 2015. Na atualidade, o Fies revela-se uma política em evidente encolhimento e de futuro incerto.

Palavras-chave: Fies. Política de Educação Superior. Políticas Públicas de Educação. Relações Público-Privado na Educação. Financiamento Estudantil.

\section{Analysis of the Relationship between the Public and Private Sectors in Higher Education within the Scope of Fies}

\section{Abstract}

The Student Financing Fund (Fies), created in 1999, has already funded over three million students. The purpose of this article is to analyze how Fies contributed to the expansion of private higher education in Brazil. - A mixed - quantitative and qualitative - research method is employed, with an emphasis on the sequential explanatory strategy model, and, in the theoretical-contextual perspective, the text represents Fies in the framework of neoliberal ideas for State action in education, in which the privatization and commodification of higher education are leveraged. Data on public expenditures on the Program and its service are examined, covering numbers of contracts, students, institutions, and territorial distribution. The 1999-2020 gap registers a significant increase in access to higher education and Fies, which started timidly, expanded significantly between 2011 and 2015. Currently, Fies reveals itself as a policy that is clearly shrinking and with an uncertain future.

Keywords: Fies. Higher Education Policy. Public Education Policies. Public-Private Relations in Education. Student Financing. 
Análise das Relações entre os Setores Público e Privado na Educação Superior no Âmbito do Fies

\section{Introdução}

Este artigo resulta de um estudo mais amplo do Fies como política pública, no período 1999-2020, o qual analisou a contribuição da política para a expansão da educação superior no Brasil no período, tendo em conta as perspectivas do financiamento público, do benefício às instituições e do perfil dos beneficiários da ponta, quer dizer, os estudantes contratantes do Fies. Para tal, a pesquisa utilizou ampla base de dados, abrangendo, entre outras, microdados do Censo da Educação Superior e do Fies, dados da execução orçamentária da União, da Caixa Econômica Federal (CEF) e do Exame Nacional de Desempenho dos Estudantes (Enade).

O recorte, no presente artigo, é o das relações entre os setores público e privado na educação superior no marco do Fies, com o objetivo de analisar como o Fies contribuiu para a expansão da educação superior privada no Brasil.

Criado através da Medida Provisória (MP) n 1.827, de 27 de maio de 1999 (BRASIL, 1999a), o Fies é um fundo "[...] de natureza contábil, destinado à concessão de financiamento a estudantes regularmente matriculados em cursos superiores não gratuitos e com avaliação positiva, de acordo com regulamentação própria, nos processos conduzidos pelo Ministério da Educação", conforme art. $1^{\circ}$ da MP à época. O Fies ainda seria remodelado pelas Portarias do MEC n 860, de 27 de maio (BRASIL, 1999f) e 1.386, de 15 de setembro (BRASIL, 1999g), além de Resolução do Conselho Monetário Nacional (CMN) $n^{\circ} 2.647$, de 22 de setembro (BRASIL, 1999d) e, com efeito, por outras três Medidas Provisórias: $\mathrm{n}^{\circ} 1.865-2$, de 29 de junho (BRASIL, 1999b); $n^{\circ}$ 1.972-8, de 10 de dezembro (BRASIL, 1999c); e $n^{\circ} 2.094-22$, em 27 de dezembro de 2000 (BRASIL, 2000), até a sua institucionalização em 2001 (BRASIL, 2001). De 2001 para cá, o Fies sofreu reformulações, em seus regramentos legais, sua política de abrangência, seu público-alvo e seu financiamento.

A partir de 2018, os recursos do Fies são repassados mensalmente pelo Fundo Nacional de Desenvolvimento da Educação (FNDE), em função direta aos contratos honrados pelos estudantes junto aos agentes financeiros credenciados no Fies, e o pagamento é realizado junto às entidades mantenedoras das instituições de ensino superior por meio de Certificados Financeiros do Tesouro - Série E (CFT-E) ${ }^{1}$ (BRASIL, 2018a). Entende-se por ordens de pagamento dessa natureza "[...] títulos públicos emitidos pelo Tesouro Nacional, intransferíveis e que devem ser utilizados prioritariamente no pagamento de contribuições previdenciárias e demais tributos administrados pela Receita Federal" (FNDE, 2018a).

Operando timidamente até 2009 , o Fies foi drasticamente reformulado através da Lei $n^{\circ}$ 12.202, de 14 de janeiro de 2010 (BRASIL, 2010a). Em linhas gerais, o “Novo Fies", como foi batizado, passou a ser controlado pelo FNDE com a prerrogativa de administrar e operar os contratos ativos e passivos do Programa. Essas mudanças seriam rápidas e fundamentais para os desdobramentos da política. Se até 2010 o orçamento do Fies orbitava em torno de $\mathrm{R} \$ 1$ bilhão anuais, os anos seguintes apresentariam rubricas de até $\mathrm{R} \$ 21$ bilhões (2017).

1 Certificados do Tesouro Nacional são emissões diretas de títulos, realizadas para o atendimento de finalidades específicas, definidas pelo Decreto $n^{\circ}$ 9.292, de 23 de fevereiro de 2018 (BRASIL, 2018a). Com relação ao tipo $\mathrm{E}$, especificamente aqueles títulos relacionados ao Fies, "terão como valor nominal múltiplo de $\mathrm{R} \$ 1,00$ (um real) e serão inegociáveis" (art. 15, Parágrafo Único). 
Análise das Relações entre os Setores Público e Privado na Educação Superior no Âmbito do Fies

Nesse momento, o Fies conta com duas modalidades: Fies, cujo agente operador é o Fundo Garantidor do Fies (FG-Fies), podendo ser acessada por estudantes com perfil de renda bruta familiar per capita de até três salários mínimos, e modalidade P-Fies, cuja responsabilidade passa a ser de agentes financeiros operadores de crédito, e "[...] não poderá ser garantida pelo FG-Fies e pode ser acessada por estudantes que tenham perfil de renda bruta familiar per capita de 3 (três) salários mínimos até 5 (cinco) salários mínimos" (BRASIL, 2018b).

$\mathrm{Na}$ sequência, o texto está organizado em quatro seções. Na primeira, são apresentadas ideias sobre o financiamento da educação superior por parte do Estado ou dos estudantes, dando relevo a argumentos de crítica ou de defesa do financiamento público da educação privada ou da cobertura dos custos por parte dos beneficiários. A metodologia da pesquisa é detalhada na continuidade, seguida de um segmento em que é reconstruída, sucintamente, a trajetória da política, com suas reformulações e são analisados os números do Fies de acordo com o objeto do artigo. Nas considerações finais, retomam-se aspectos essenciais das reformulações do Fies e são discutidos seus controversos benefícios diante da expansão do acesso à educação superior, das suas prioridades e do que envolve em termos de relações entre os setores público e privado na educação superior.

\section{Discursos sobre o privado financiamento público da educação superior}

Uma vez que o Fies caracteriza-se pela transferência de valores da União para instituições de ensino superior privadas, é mister expor alguns constructos acerca das relações entre os setores público e privado na educação. Esta exposição não constitui um panorama, todavia, é guiada pela intenção de situar a política num contexto de ideias e de fenômenos que ocorrem no movimento de imbricação entre os setores estatal e privado na educação superior brasileira.

Para Sérgio Adorno (1991, p. 9) "[...] a história da educação na sociedade brasileira é atravessada pela interpenetração das esferas privada e pública da existência coletiva". Ainda segundo o mesmo autor, "[...] ao construir um discurso que desqualifica a educação pública, os responsáveis pelos estabelecimentos privados procuram legitimar-se no campo educacional e, através dessa elaboração e das práticas a ela ajustadas, visam a aumentar seu raio de influência e de atuação" (ADORNO, 1991, p. 6-7). Tal discurso está presente ao longo do tempo, e manifesto nos dias atuais. Adorno (1991, p. 10-11) afirma que o maior problema não é a privatização do público, "[...] mas a publicização de um projeto educativo particular, imaginado pelas classes dominantes como capaz de colocar a sociedade brasileira em compasso com o progresso em voga nas sociedades situadas no centro do desenvolvimento capitalista". A desqualificação, ou descaracterização, da educação superior, em específico, tem por objetivo, para Minto (2006, p. 247), "[...] facilitar a entrada e determinação desta ao capital, como atividade dirigida para os fins de acumulação".

Lima (2007, p. 65) situa o fortalecimento da concepção da oferta privada de educação superior no contexto do neoliberalismo da Terceira Via, e no papel desempenhado pelo Banco Mundial na disseminação de ideias. Em documento do Banco Mundial de 1997, lê-se: "[...] algumas vezes os governos gastam muito mais em educação superior para os estudantes ricos e de classe média, do que em educação básica para a maioria da população e com 
bolsas para os mais necessitados" (WORLD BANK, 1997, p. 116). Contudo, foi no texto Higher education: the lessons of experience (WORLD BANK, 1995, p. 20) que o órgão defendeu que países em desenvolvimento deveriam capitalizar orçamento e esforços na educação básica, e terceirizar o ensino superior à iniciativa privada. Ainda de acordo com Lima (2007, p. 66), esse Relatório estabelece dois eixos norteadores para a educação superior: "[...] a diversificação das instituições de ensino superior e dos cursos e a diversificação das fontes de financiamento".

Em junho de 2003 ocorreria outro marco do processo de reformulação da educação superior: a Conferência Mundial sobre Educação Superior +5 , em Paris, promovida pela Organização das Nações Unidas para a Educação, a Ciência e a Cultura (Unesco), como um reencontro-balanço do mesmo evento, ocorrido em 1998. No Relatório disponibilizado (UNESCO, 2003, p. 93-150), o órgão reforça a importância do ensino a distância para a difusão da educação superior, e, no que se refere ao financiamento, "A tendência geral revelada pelos relatórios regionais é diversificar as fontes de financiamento, recorrendo aos beneficiários diretos para compartilhar os custos envolvidos: estudantes e suas famílias, empresas, indústria e o setor público em geral" (UNESCO, 2003, p. 113). Em suas conclusões, porém, o Relatório sinaliza que a tendência de criação de um mercado da educação superior de dimensões globais deveria ser examinada com cautela.

Essa nova visão de educação mundial parece ter um marco inicial: 1991, quando uma faculdade norte-americana "[...] chamada DeVry tornou-se a primeira instituição de ensino no mundo a abrir seu capital em bolsa de valores. Era o primeiro passo de um processo, agora visivelmente inevitável, de atração mútua entre dois prováveis parceiros: o setor da educação e o mercado financeiro" (MIZNE, 2004, p. 125). Segundo o autor, no Brasil, em 2003, houve movimentação de mais de $\mathrm{R} \$ 100$ bilhões de reais no setor educacional, ou "mais de $9 \%$ do PIB, afetando diretamente a vida de mais de 60 milhões de alunos e 50 milhões de pais" (MIZNE, 2004, p. 126).

Mizne (2004) oferece farto quadro estatístico para sustentar a afirmação de o quanto o mercado educacional terciário brasileiro, em 2004, seria o mercado do futuro. Para o autor, há duas razões que garantiriam "esse crescimento projetado": a primeira, se refere aos investimentos feitos na educação básica, que conduziriam até quatro milhões de estudantes ao ensino superior em 2010; a segunda, é o que chama de "[...] deselitização da educação superior, e a ideia de que o processo educacional acompanhará o brasileiro durante grande parte de sua vida profissional" (MIZNE, 2004, p. 130).

Todavia, Minto (2006, p. 249-250) alerta que a expansão da educação superior privada demandaria, indubitavelmente, recursos públicos em proporção crescente "expressão de que, sem obter tais verbas, o setor sequer pode se manter". A esse fenômeno o autor chama "complementaridade", viabilizada através do financiamento direto e indireto. Argumentos favoráveis ao financiamento público da educação privada proliferam, podendo ser exemplificados na obra de Abib Salim Cury (2010), para quem a iniciativa privada seria a via para atender a demanda por educação superior gerada pela expansão da educação básica.

Outro viés é o de Mendes (2014, p. 202), que defende o pagamento do ensino superior sob o argumento de que "[...] o ensino universitário público brasileiro é tradicionalmente elitista, sendo majoritariamente frequentado por estudantes de classe média e alta". O autor prescreve que "[...] a cobrança de anuidades aos alunos universitários poderia cobrir custos 
Análise das Relações entre os Setores Público e Privado na Educação Superior no Âmbito do Fies

de seu ensino, liberando verbas a serem aplicadas na educação básica, melhorando a sua qualidade e elevando o nível geral de ensino", além de considerar que um sistema geral de bolsas de estudos aos alunos sem capacidade financeira "poderia solucionar o problema da inclusão social".

Cabe acrescentar aqui as considerações de Sampaio (2014, p. 144) sobre a combinação, no Brasil, de alto percentual de matrículas na educação superior privada (75\%) com a alocação de recursos públicos para o financiamento estudantil na rede privada. Sampaio (2014, p. 184) argumenta que "[...] as diferenças entre o setor público e o privado, até muito recentemente percebidas como bastante nítidas, tendem a se tornar mais nuançadas". Isso ocorre em função das demandas de mercado no ensino superior e de políticas de ampliação do acesso, o que termina por aproximar os setores público e privado e, no âmbito do setor privado, aproximar os segmentos sem e com finalidade lucrativa.

O Fies representa mais um capítulo, ou uma faceta, da interpenetração entre os setores público e privado na educação brasileira. Associa a ideia de que os estudantes devem arcar com as despesas de sua formação de nível superior, pois é um empréstimo que deve ser pago, e a ideia e a prática da presença forte do Estado no financiamento da educação particular, pois os ganhos deste segmento com o Fundo são em parte financiados com recursos públicos, dado o subsídio implícito. Os estudantes contratantes do Fies obtêm benefício, pois é viabilizado seu acesso à educação superior; as instituições particulares também, e esta é a particularidade examinada neste artigo.

\section{Metodologia da pesquisa}

O método de pesquisa adotado foi o misto, combinado à técnica de triangulação de dados. Apresentado em 2003 no Handbook of Mixed Methods in the Social e Behavior Sciences (TASHAKORI; TEDDIE, 2003 apud CRESWELL, 2010, p. 239), essa técnica emprega uma estratégia de investigação que combina abordagens quantitativas e qualitativas, utilizando os pontos fortes que cada uma tem a oferecer (CRESWELL, 2010, p. 238). Mais especificamente, foi utilizado o modelo de estratégia explanatória sequencial, descrita por Creswell (2010, p. 247) como estratégia para "[...] pesquisadores com fortes inclinações quantitativas, caracterizada pela coleta e análise de dados quantitativos em uma primeira etapa da pesquisa, seguidas de coleta e análise de dados qualitativos em uma segunda fase que é desenvolvida sobre os resultados quantitativos iniciais". Assim, o uso desse modelo enseja que os dados quantitativos conduzam a uma análise qualitativa, permitindo um estudo mais apurado dos resultados quando surgem informações inesperadas na primeira fase (MORSE, 1991, p. 121).

Frente ao modelo proposto, optou-se pela coleta de dados sequencial, combinando os resultados obtidos à análise da política, utilizando dados econômicos e fiscais e a atribuição de pesos e percentuais, que facilitassem a exposição dos achados. Dentro da combinação de diferentes abordagens, utilizou-se a triangulação de dados como recurso de validação (DENZIN, 1989 apud FLICK, 2013, p. 182).

Consideram-se os indicadores utilizados para correlacionar os dados do Fies como inputs, agrupados em quatro containers, assim: a) inputs sociais: matrículas por ano, gênero, faixa etária, estado civil, raça/cor, ensino médio em escola pública, pessoas com deficiência (PcD) e tipo de curso; b) inputs econômicos: proporções de concessão de bolsas, proporções 
de concessão de financiamentos, orçamento executado por ano e valor por aluno por ano; c) inputs tributários: emissão, recompra e repasse de títulos CFT-E, agente financeiro, fundos garantidores e tipos de fiança contratualizadas, integralização de cotas, administração do programa e subsídio implícito; e d) input perfil socioeconômico dos contratantes do Fies: escolaridade familiar, situação de moradia, renda pessoal e familiar, situação de emprego e opção de curso, participação em grupos de pesquisa ou extensão, modalidade e tipo de ensino médio, incentivos e entraves familiares e livros lidos e horas de estudo durante a graduação.

Uma vez definidos os fatores de análise, a etapa de coleta de dados também percorreu quatro frentes (econômica, fiscal, educacional e social), agrupada em dois segmentos. No primeiro, a obtenção de uma visão panorâmica da educação superior brasileira, pública e privada, presencial e a distância; as matrículas federais; as bolsas do Prouni concedidas e os contratos e aditamentos do Fies firmados, o que permitiu observar o comportamento da educação superior, sob múltiplos aspectos, e a respectiva influência das políticas federais de financiamento. Outro segmento diz respeito à exploração de aspectos econômicos, contratuais, fiscais e sociais do Fies, respectivamente. Enquanto as perspectivas econômica e fiscal reuniram dados referentes aos investimentos monetários da política, nos contratos foram buscados os números em torno da formalização, ou melhor, do credenciamento das pessoas cujas características sociais são contrastadas às dos estudantes do Prouni e da educação superior brasileira, buscando insulamentos e aproximações. Também foi utilizada a base do Enade para acessar dados pessoais dos(as) estudantes.

Para cada cenário - panorama e exploração -, uma trajetória foi percorrida, muito embora, para sua construção, essas fontes fossem revisitadas, ou melhor, reesgotadas. 0 Fies, como política social cujo objetivo primário é a concessão de empréstimos bancários, com respectiva devolução ao erário, envolve considerável quantidade de informações financeiras, contábeis, fiscais e sociais. A reunião dos dados para uma análise consolidada, contudo, requer a triangulação de diferentes fontes, podendo ser divididas em quatro grandes grupos: execução financeira, custeio e administração, subsídio implícito e indicadores sociais.

A execução financeira do Fies refere-se às rubricas de emissão, repasse e recompra de títulos públicos, aos repasses aos fundos garantidores, administrados pelo Banco do Brasil, até $1^{\circ}$ de julho de 2018, e pela Caixa Econômica Federal desde então. O custeio trata da integralização de cotas aos Fundos Garantidores, pela Administração Federal, e a administração engloba a despesa para a operacionalização dos contratos pelos bancos públicos. O subsídio implícito, a seu tempo, é, em termos tributários, um tipo de benefício creditício praticado pela Administração Pública em que a diferença entre o que é emprestado e o que é efetivamente pago (o retorno) resulta em soma menor que zero, ou, em outras palavras, prejuízo.

\section{O Fies, suas reformulações e seus números}

Em linhas muito breves, o Fies opera na combinação da expansão da educação superior com a adimplência das instituições privadas de ensino superior, assim: o Fies solicita ao Tesouro Nacional a emissão de uma quantidade e valor de CFTs, descritos anteriormente, e paga ao Tesouro com recursos próprios. Esses títulos, por sua vez, são emitidos às 
instituições e resgatados em tempos específicos, como forma de pagamento de tributos que os entes têm com a União. De acordo com a Lei que institui a política (BRASIL, 2001):

O Fies entrega os títulos às escolas, em valor equivalente ao pagamento das mensalidades (art. $9^{\circ}$ ) e passa a ter um crédito junto ao aluno financiado, que repagará o empréstimo no prazo contratado. Todas as amortizações feitas pelos alunos entram no orçamento do Fies como receita vinculada ao Fundo.

A escola utiliza os títulos exclusivamente para o pagamento de tributos e contribuições previdenciárias - art. 10.

Para atender ao caso em que haja escolas com mais CFT do que dívidas tributárias e previdenciárias a pagar, o Fundo Nacional de Desenvolvimento da Educação (FNDE), agente operador do Fies, promove rodadas trimestrais de recompra desses títulos, pagando em dinheiro às escolas - art. 13.

A Tabela 1 mapeia a evolução da educação superior desde 1980 e sua correlação ao Fies, a partir de 1999 até 2019 (consolidado).

Tabela 1 - Evolução das matrículas Brasil (1980-2018) e dos contratos Fies (1999-2019)

\begin{tabular}{|c|c|c|c|c|c|c|c|c|c|c|c|c|c|c|}
\hline \multirow[b]{3}{*}{ Ano } & \multicolumn{6}{|c|}{ ¿ MATRÍCULAS EDUCAÇÃO SUPERIOR } & \multicolumn{8}{|c|}{$\Sigma$ FIES } \\
\hline & \multicolumn{5}{|c|}{ Presenciais e EAD } & \multirow{2}{*}{\begin{tabular}{|l|} 
Presenciais \\
Privadas (E) \\
\end{tabular}} & \multicolumn{4}{|c|}{ Vagas } & \multicolumn{4}{|c|}{ Contratos } \\
\hline & Públicas (A) & Privadas (B) & \begin{tabular}{|c|} 
Públicas e \\
Privadas \\
$(\mathbf{C}=\mathbf{A}+\mathbf{B})$
\end{tabular} & $\begin{array}{c}\begin{array}{c}\% \text { Públicas } \\
\text { Brasil }\end{array} \\
\text { a }\end{array}$ & \begin{tabular}{|c|}
$\%$ Privadas \\
Brasil
\end{tabular} & & \begin{tabular}{|c|} 
Vagas \\
Oferecidas \\
(1)
\end{tabular} & $\begin{array}{r}\text { Evolução (2) / } \\
\text { ano anterior }\end{array}$ & Novas (3) & $\begin{array}{c}\text { Evolução (4) / } \\
\text { ano anterior }\end{array}$ & $\begin{array}{c}\text { Ativos } \\
\text { [RA's] (5) }\end{array}$ & \begin{tabular}{|c|}
$\%$ FIES \\
Brasil \\
Privadas \\
Presenciais \\
\end{tabular} & $\begin{array}{c}\text { Crescimento (6) } \\
\text { / ano anterior }\end{array}$ & Microdados (7) \\
\hline 1980 & 492.232 & 885.054 & 1.377 .286 & $35,74 \%$ & $64,26 \%$ & & & & & & & & & \\
\hline 1981 & 535.810 & 850.982 & 1.386 .792 & $38,64 \%$ & $61,36 \%$ & & & & & & & & & \\
\hline 1982 & 548.388 & 859.599 & 1.407 .987 & $38,95 \%$ & $61,05 \%$ & & & & & & & & & \\
\hline 1983 & 576.689 & 862.303 & 1.438 .992 & $40,08 \%$ & $59,92 \%$ & & & & & & & & & \\
\hline 1984 & 571.879 & 827.660 & 1.399 .539 & $40,86 \%$ & $59,14 \%$ & & & & & & & & & \\
\hline 1985 & 556.680 & 810.929 & 1.367 .609 & $40,70 \%$ & $59,30 \%$ & & & & & & & & & \\
\hline 1986 & 577.632 & 840.564 & 1.418 .196 & $40,73 \%$ & $59,27 \%$ & & & & & & & & & \\
\hline 1987 & 584.965 & 885.590 & 1.470 .555 & $39,78 \%$ & $60,22 \%$ & & & & & & & & & \\
\hline 1988 & 585.351 & 918.209 & 1.503 .560 & $38,93 \%$ & $61,07 \%$ & & & & & & & & & \\
\hline 1989 & 584.414 & 934.490 & \begin{tabular}{|l|}
1.518 .904 \\
\end{tabular} & $38,48 \%$ & $61,52 \%$ & & & & & & & & & \\
\hline 1990 & 578.625 & 961.455 & \begin{tabular}{|l|}
1.540 .080 \\
\end{tabular} & $37,57 \%$ & $62,43 \%$ & & & & & & & & & \\
\hline 1991 & 605.736 & 959.320 & 1.565 .056 & $38,70 \%$ & $61,30 \%$ & & & & & & & & & \\
\hline 1992 & 629.662 & 906.126 & \begin{tabular}{|l|}
1.535 .788 \\
\end{tabular} & $41,00 \%$ & $59,00 \%$ & & & & & & & & & \\
\hline 1993 & 653.516 & 941.152 & \begin{tabular}{|l|}
1.594 .668 \\
\end{tabular} & $40,98 \%$ & $59,02 \%$ & & & & & & & & & \\
\hline 1994 & 690.450 & 970.584 & \begin{tabular}{|l|}
1.661 .034 \\
\end{tabular} & $41,57 \%$ & $58,43 \%$ & & & & & & & & & \\
\hline 1995 & 700.540 & 1.059 .163 & 1.759 .703 & $39,81 \%$ & $60,19 \%$ & & & & & & & & & \\
\hline 1996 & 735.427 & 1.133 .102 & 1.868 .529 & $39,36 \%$ & $60,64 \%$ & & & & & & & & & \\
\hline 1997 & 759.182 & 1.186 .433 & \begin{tabular}{|l|}
1.945 .615 \\
\end{tabular} & $39,02 \%$ & $60,98 \%$ & & & & & & & & & \\
\hline 1998 & 804.729 & 1.321 .229 & 2.125 .958 & $37,85 \%$ & $62,15 \%$ & & & & & & & & & \\
\hline 1999 & 832.022 & 1.537 .923 & 2.369 .945 & $35,11 \%$ & $64,89 \%$ & 1.537 .923 & & & 67.202 & & 67.202 & $4,37 \%$ & & \\
\hline 2000 & 888.708 & 1.807 .219 & \begin{tabular}{|l|}
2.695 .927 \\
\end{tabular} & $32,96 \%$ & $67,04 \%$ & 1.807 .219 & 100.000 & & 35.299 & $-47,47 \%$ & 102.501 & $5,67 \%$ & $52,53 \%$ & \\
\hline 2001 & 944.589 & 2.091 .524 & 3.036 .113 & $31,11 \%$ & $68,89 \%$ & 2.091 .524 & 60.000 & $-40,00 \%$ & 48.456 & $37,27 \%$ & 150.677 & $7,20 \%$ & $47,00 \%$ & \\
\hline 2002 & 1.085 .977 & 2.434 .650 & \begin{tabular}{|l|}
3.520 .627 \\
\end{tabular} & $30,85 \%$ & $69,15 \%$ & 2.428 .258 & 80.000 & $33,33 \%$ & 65.808 & $35,81 \%$ & 218.775 & $9,01 \%$ & $45,19 \%$ & \\
\hline 2003 & 1.178 .573 & 2.758 .360 & 3.936 .933 & $29,94 \%$ & $70,06 \%$ & 2.750 .652 & 70.000 & $-12,50 \%$ & 49.248 & $-25,16 \%$ & 271.992 & $9,89 \%$ & $24,32 \%$ & \\
\hline 2004 & 1.214 .317 & 3.009 .027 & 4.223 .344 & $28,75 \%$ & $71,25 \%$ & 2.985 .405 & 50.000 & $-28,57 \%$ & 42.216 & $-14,28 \%$ & 312.027 & $10,45 \%$ & $14,72 \%$ & \\
\hline 2005 & 1.227 .788 & 3.340 .010 & \begin{tabular}{|l|}
4.567 .798 \\
\end{tabular} & $26,88 \%$ & $73,12 \%$ & 3.260 .967 & 100.000 & $100,00 \%$ & 77.202 & $82,87 \%$ & 372.038 & $11,41 \%$ & $19,23 \%$ & \\
\hline 2006 & 1.247 .733 & 3.636 .904 & \begin{tabular}{|l|}
4.884 .637 \\
\end{tabular} & $25,55 \%$ & $74,47 \%$ & 3.467 .342 & 100.000 & $0,00 \%$ & 58.259 & $-24,54 \%$ & 377.662 & $10,89 \%$ & $1,51 \%$ & \\
\hline 2007 & 1.276 .752 & 3.973 .395 & 5.250 .147 & $24,32 \%$ & $75,68 \%$ & 3.639 .413 & 100.000 & $0,00 \%$ & 47.900 & $-17,78 \%$ & 425.001 & $11,68 \%$ & $12,53 \%$ & \\
\hline 2008 & 1.552 .953 & 4.255 .064 & \begin{tabular}{|l|}
5.808 .017 \\
\end{tabular} & $26,74 \%$ & $73,26 \%$ & 3.806 .091 & 100.000 & $0,00 \%$ & 32.384 & $-32,39 \%$ & \begin{tabular}{|l|}
473.340 \\
\end{tabular} & $12,44 \%$ & $11,37 \%$ & \\
\hline 2009 & 1.523 .864 & 4.430 .157 & \begin{tabular}{|l|}
5.954 .021 \\
\end{tabular} & $25,59 \%$ & $74,41 \%$ & 3.764 .728 & 100.000 & $0,00 \%$ & 32.781 & $1,23 \%$ & 486.718 & $12,93 \%$ & $2,83 \%$ & \\
\hline 2010 & 1.643 .298 & 4.736 .001 & 6.379 .299 & $25,76 \%$ & $74,24 \%$ & 3.987 .424 & 200.000 & $100,00 \%$ & 71.611 & $118,45 \%$ & 529.553 & $13,28 \%$ & $8,80 \%$ & \\
\hline 2011 & 1.773 .315 & 4.966 .374 & 6.739 .689 & $26,31 \%$ & $73,69 \%$ & 4.151 .371 & 415.000 & $107,50 \%$ & 153.151 & $113,87 \%$ & 583.757 & $14,06 \%$ & $10,24 \%$ & 309.889 \\
\hline 2012 & 1.897 .376 & 5.140 .312 & \begin{tabular}{|l|}
7.037 .688 \\
\end{tabular} & $26,96 \%$ & $73,04 \%$ & 4.208 .086 & 502.500 & $21,08 \%$ & \begin{tabular}{|l|}
377.780 \\
\end{tabular} & $146,67 \%$ & \begin{tabular}{|l|}
918.137 \\
\end{tabular} & $21,82 \%$ & $57,28 \%$ & 583.596 \\
\hline 2013 & 1.932 .527 & 5.373 .450 & \begin{tabular}{|l|}
7.305 .977 \\
\end{tabular} & $26,45 \%$ & $73,55 \%$ & 4.374 .431 & 875.000 & $74,13 \%$ & \begin{tabular}{|l|}
559.905 \\
\end{tabular} & $48,21 \%$ & \begin{tabular}{|l|}
1.168 .100 \\
\end{tabular} & $26,70 \%$ & $27,23 \%$ & 1.725 .369 \\
\hline 2014 & 1.961 .002 & 5.867 .011 & \begin{tabular}{|l|}
7.828 .013 \\
\end{tabular} & $25,05 \%$ & $74,95 \%$ & 4.664 .542 & 600.512 & $-31,37 \%$ & 732.494 & $30,82 \%$ & \begin{tabular}{|l|}
1.910 .718 \\
\end{tabular} & $40,96 \%$ & $63,57 \%$ & 2.801 .042 \\
\hline 2015 & 1.952 .145 & 6.075 .152 & 8.027 .297 & $24,32 \%$ & $75,68 \%$ & 4.809 .793 & 313.947 & $-47,72 \%$ & 287.367 & $-60,77 \%$ & 2.185 .038 & $45,43 \%$ & $14,36 \%$ & 2.995 .270 \\
\hline 2016 & 1.990 .078 & 6.058 .623 & \begin{tabular}{|l|}
8.048 .701 \\
\end{tabular} & $24,73 \%$ & $75,27 \%$ & 4.686 .806 & 325.279 & $3,61 \%$ & 198.189 & $-31,03 \%$ & \begin{tabular}{|l|}
2.441 .008 \\
\end{tabular} & $52,08 \%$ & $11,71 \%$ & 2.359 .266 \\
\hline 2017 & 2.045 .356 & 6.240 .982 & 8.286 .338 & $24,68 \%$ & $75,32 \%$ & 4.649 .897 & 225.000 & $-30,83 \%$ & \begin{tabular}{|l|}
175.925 \\
\end{tabular} & $-13,77 \%$ & \begin{tabular}{|l|}
2.765 .439 \\
\end{tabular} & $59,47 \%$ & $10,61 \%$ & 2.693 .934 \\
\hline 2018 & 2.077 .481 & 6.372 .040 & \begin{tabular}{|l|}
8.449 .521 \\
\end{tabular} & $24,59 \%$ & $75,41 \%$ & 4.489 .690 & 310.000 & $37,78 \%$ & 60.618 & $-34,61 \%$ & 2.554 .998 & $40,45 \%$ & $-34,32 \%$ & 1.808 .453 \\
\hline 2019 & & & & & & & & & & $-61,83 \%$ & \begin{tabular}{|l|}
690.220 \\
\end{tabular} & & & 690.220 \\
\hline
\end{tabular}

Fonte: Elaborada pelos autores (2020). Vide nota ${ }^{2}$.

2 Matrículas da Educação Superior: INEP (1999a; 1999b; 2007; 2008; 2009; 2010; 2011; 2012; 2013; 2014; 2015; 2016; 2000b; 2017; 2018; 2000a; 2001; 2002; 2003; 2004; 2005; 2006). Vagas e Contratos Fies - Relatórios de Gestão: (BRASIL, 2008; 2009b; 1999h; 2010c; 2011b; 2012; 2013; 2014b; 2015; 2016; 2017c; BRASIL; 
A Tabela 11 enseja uma análise mais detalhada da evolução do Fies em três tempos até 2010 , entre 2010 e 2014 e, por fim, entre 2015 e 2019: de um modo geral, as matrículas na educação superior crescem progressivamente desde 1980 , com expansão de $613,49 \%$ no período analisado (1980-2018), com especial atenção à expansão da modalidade de educação a distância (EAD), que acusa espetacular evolução desde o início dos registros, em 2000: $1.221,92 \%$ até o último censo disponível (2018); a oferta privada retém $91,6 \%$ dos registros de EAD em 2018, conforme disposto na Tabela 2.

Tabela 2 - Evolução das matrículas Brasil, presencial e EAD, públicas e privadas (1999-2018)

\begin{tabular}{|c|c|c|c|c|c|c|c|c|c|c|c|c|c|c|c|}
\hline \multirow[b]{3}{*}{ Ano } & \multicolumn{15}{|c|}{$\Sigma$ MATRÍCULAS EDUCAÇÃO SUPERIOR } \\
\hline & \multicolumn{5}{|c|}{ Presenciais e EAD } & \multicolumn{5}{|c|}{ Presenciais } & \multicolumn{5}{|c|}{ EAD } \\
\hline & Públicas (A) & Privadas (B) & \begin{tabular}{|c|} 
Públicas e \\
Privadas \\
$(\mathbf{C}=\mathbf{A}+\mathbf{B})$ \\
\end{tabular} & $\begin{array}{c}\% \text { Públicas } \\
\text { Brasil }\end{array}$ & $\begin{array}{c}\% \text { Privadas } \\
\text { Brasil }\end{array}$ & Públicas (D) & Privadas (E) & $\begin{array}{c}\text { Presenciais } \\
(\mathrm{F}=\mathrm{D}+\mathrm{E})\end{array}$ & $\begin{array}{l}\% \text { Privadas } \\
\text { Presenciais }\end{array}$ & \begin{tabular}{|c|}
$\%$ \\
Presenciais \\
Brasil
\end{tabular} & $\begin{array}{c}\text { Públicas } \\
\text { (G) }\end{array}$ & Privadas $(\mathrm{H})$ & $\underset{\substack{\text { EAD } \\
(=\mathbf{G}+\mathbf{H})}}{2}$ & $\begin{array}{c}\% \text { Privadas } \\
\text { EAD }\end{array}$ & $\begin{array}{r}\% \text { EAD } \\
\text { Brasil }\end{array}$ \\
\hline 1999 & 832.022 & 1.537 .923 & 2.369 .945 & $35,11 \%$ & $64,89 \%$ & 832.022 & \begin{tabular}{|l|} 
\\
\end{tabular} & 2.369 .945 & $64,89 \%$ & $100,00 \%$ & 0 & 0 & 0 & $0,00 \%$ & $0,00 \%$ \\
\hline 2000 & 8.708 & 1.807 .219 & 2.695 .927 & $32,96 \%$ & $67,04 \%$ & 887.026 & \begin{tabular}{|l|l|} 
& 1.807 .219 \\
\end{tabular} & 2.694 .245 & $67,08 \%$ & $99,94 \%$ & 1.682 & 0 & 1.682 & $0,00 \%$ & $0,06 \%$ \\
\hline 2001 & 944.589 & 2.091 .524 & 3.036 .113 & $31,11 \%$ & $68,89 \%$ & 939.230 & 2.091 .524 & 3.030 .754 & $69,01 \%$ & $99,82 \%$ & 5.359 & 0 & 5.359 & $0,00 \%$ & $0,18 \%$ \\
\hline 2002 & 1.085 .977 & 2.434 .650 & 3.520 .627 & $30,85 \%$ & $69,15 \%$ & 1.051 .655 & 2.428 .258 & 3.479 .913 & $69,78 \%$ & $98,84 \%$ & 34.322 & 6.392 & 40.714 & $15,70 \%$ & $1,16 \%$ \\
\hline 2003 & 1.178 .573 & 2.758 .360 & \begin{tabular}{|l|}
3.936 .933 \\
\end{tabular} & $29,94 \%$ & $70,06 \%$ & 1.136 .370 & 2.750 .652 & 3.887 .022 & $70,77 \%$ & $98,73 \%$ & 42.203 & 7.708 & 49.911 & $15,44 \%$ & $1,27 \%$ \\
\hline 2004 & 1.214 .317 & 3.009 .027 & 4.223 .344 & $28,75 \%$ & $71,25 \%$ & 1.178 .328 & 2.985 .405 & 4.163 .733 & $71,70 \%$ & $98,59 \%$ & 35.989 & 23.622 & 59.611 & $39,63 \%$ & $1,41 \%$ \\
\hline 2005 & 1.227 .788 & 3.340 .010 & 4.567 .798 & $26,88 \%$ & $73,12 \%$ & 1.192 .189 & 3.260 .967 & 4.453 .156 & $73,23 \%$ & $97,49 \%$ & 35.599 & 79.043 & 114.642 & $68,95 \%$ & $2,51 \%$ \\
\hline 2006 & 1.247 .733 & 3.636 .904 & \begin{tabular}{|l|}
4.884 .637 \\
\end{tabular} & $25,55 \%$ & $74,47 \%$ & 1.209 .304 & $\begin{array}{l}3.467 .342 \\
\end{array}$ & 4.676 .646 & $74,14 \%$ & $95,76 \%$ & 38.429 & 169.562 & 207.991 & $81,52 \%$ & $4,26 \%$ \\
\hline 2007 & 1.276 .752 & 3.973 .395 & 5.250 .147 & $24,32 \%$ & $75,68 \%$ & 1.240 .968 & 3.639 .413 & 4.880 .381 & $74,57 \%$ & $92,96 \%$ & 35.784 & 333.982 & 369.766 & $90,32 \%$ & $7,04 \%$ \\
\hline 2008 & 1.552 .953 & 4.255 .064 & 5.808 .017 & $26,74 \%$ & $73,26 \%$ & 1.273 .965 & 3.806 .091 & 5.080 .056 & $74,92 \%$ & $87,47 \%$ & 278.988 & 448.973 & 727.961 & $61,68 \%$ & $12,53 \%$ \\
\hline 2009 & 1.523 .864 & 4.430 .157 & 5.954 .021 & $25,59 \%$ & $74,41 \%$ & 1.351 .168 & 3.764 .728 & 5.115 .896 & $73,59 \%$ & $85,92 \%$ & 172.696 & 665.429 & 838.125 & $79,39 \%$ & $14,08 \%$ \\
\hline 2010 & 1.643 .298 & 4.736 .001 & \begin{tabular}{|l|}
6.379 .299 \\
\end{tabular} & $25,76 \%$ & $74,24 \%$ & 1.461 .696 & 3.987 .424 & 5.449 .120 & $73,18 \%$ & $85,42 \%$ & 181.602 & 748.577 & 930.179 & $80,48 \%$ & $14,58 \%$ \\
\hline 2011 & 1.773 .315 & 4.966 .374 & \begin{tabular}{|l|}
6.739 .689 \\
\end{tabular} & $26,31 \%$ & $73,69 \%$ & 1.595 .391 & 4.151 .371 & 5.746 .762 & $72,24 \%$ & $85,27 \%$ & 177.924 & 815.003 & 992.927 & $82,08 \%$ & $14,73 \%$ \\
\hline 2012 & 1.897 .376 & 5.140 .312 & 7.037 .688 & $26,96 \%$ & $73,04 \%$ & 1.715 .752 & 4.208 .086 & 5.923 .838 & $71,04 \%$ & $84,17 \%$ & 181.624 & 932.226 & 1.113 .850 & $83,69 \%$ & $15,83 \%$ \\
\hline 2013 & 1.932 .527 & 5.373 .450 & \begin{tabular}{|l|}
7.305 .977 \\
\end{tabular} & $26,45 \%$ & $73,55 \%$ & 1.777 .974 & 4.374 .431 & 6.152 .405 & $71,10 \%$ & $84,21 \%$ & 154.553 & 999.019 & 1.153 .572 & $86,60 \%$ & $15,79 \%$ \\
\hline 2014 & 1.961 .002 & 5.867 .011 & \begin{tabular}{|l|}
7.828 .013 \\
\end{tabular} & $25,05 \%$ & $74,95 \%$ & 1.821 .629 & 4.664 .542 & 6.486 .171 & $71,92 \%$ & $82,86 \%$ & 139.373 & 1.202 .469 & 1.341 .842 & $89,61 \%$ & $17,14 \%$ \\
\hline 2015 & 1.952 .145 & 6.075 .152 & \begin{tabular}{|l|}
8.027 .297 \\
\end{tabular} & $24,32 \%$ & $75,68 \%$ & 1.823 .752 & \begin{tabular}{|l|}
4.809 .793 \\
\end{tabular} & 6.633 .545 & $72,51 \%$ & $82,64 \%$ & 128.393 & 1.265 .359 & \begin{tabular}{|l|}
1.393 .752 \\
\end{tabular} & $90,79 \%$ & $17,36 \%$ \\
\hline 2016 & 1.990 .078 & 6.058 .623 & \begin{tabular}{|l|}
8.048 .701 \\
\end{tabular} & $24,73 \%$ & $75,27 \%$ & 1.867 .477 & 4.686 .806 & 6.554 .283 & $71,51 \%$ & $81,43 \%$ & 122.601 & 1.371 .817 & 1.494 .418 & $91,80 \%$ & $18,57 \%$ \\
\hline 2017 & 2.045 .356 & 6.240 .982 & 8.286 .338 & $24,68 \%$ & $75,32 \%$ & 1.879 .784 & 4.649 .897 & 6.529 .681 & $71,21 \%$ & $78,80 \%$ & 165.572 & 1.591 .085 & \begin{tabular}{|l|}
1.756 .657 \\
\end{tabular} & $90,57 \%$ & $21,20 \%$ \\
\hline 2018 & 2.077 .481 & 6.372 .040 & 8.449 .521 & $24,59 \%$ & $75,41 \%$ & 1.904 .554 & 4.489 .690 & 6.394 .244 & $70,21 \%$ & $75,68 \%$ & 172.927 & 1.882 .350 & 2.055 .277 & $91,59 \%$ & $24,32 \%$ \\
\hline
\end{tabular}

Fonte: Elaborada pelos autores (2020), a partir de INEP (1999a; 1999b; 2000a; 2001; 2002; 2003; 2004; 2005; 2006; 2007; 2008; 2009; 2010; 2011; 2012; 2013; 2014; 2015; 2016; 2000b; 2017; 2018).

Com relação ao Fies, é possível confirmar que até 2009 a política estava à procura de espaço e afirmação no cenário educacional, com poucos contratos assinados, e permanentes movimentos do agente operador, CEF, a fim de expandir a divulgação e o acesso, conforme descrito em seus Relatórios de Gestão. Entre 1999 e 2010, mesmo ofertando crescente número de vagas, as adesões sempre frustravam as campanhas, tanto que, caso se observe a oferta (860.000) e os contratos firmados (556.755) (entre 1999 e 2009), há um notório desinteresse, o que obrigaria o MEC a flexibilizar o sistema. Para isso, o "Novo Fies" seria o veículo.

Em entrevista realizada em 3 de maio de 2010, Fernando Haddad, ministro da Educação à época, propalou amplamente na mídia que o "Novo Fies" teria prestação fixa até o final do financiamento, a despeito da flutuação da inflação e da taxa de juros. Em suas palavras, "[...] o contrato feito a partir de agora implica prestações fixas até o final. É preciso frisar isso para evitar que o aluno tenha medo de contratar o financiamento" (SANTOS, 2010). Quanto à alteração no regramento do sistema de inscrições, que deixaria de ter uma janela de prazos

CEF, 2001; 2002; CEF, 2000; 2003; 2004; 2005; 2006; 2007), (FNDE, 2018b; 2018c; 2019b; 2019c). Contratos Ativos (2007): arbitrado pelos autores, sobre a média de contratos ativos entre 2006 e 2008, respectivamente, pois não foi localizado o total exato em qualquer fonte utilizada para os demais registros. Contratos novos (2017 e 2018) (FNDE, 2018d). Contratos ativos (2017) (FNDE, 2018a). Microdados, para os anos 2011 a 2019 : (FNDE, 2011a; 2011b; 2016a; 2016b; 2017a; 2017b; 2018b; 2018c; 2019b; 2019c; 2012a; 2012b; 2013a; 2013b; 2014a; 2014b; 2015a; 2015b). 
definida, o Ministro defendeu que a mudança poderia "[...] ajudar um estudante que sofre com alguma fatalidade e não pode ficar ao sabor do calendário para resolver seu problema".

Haddad sustentava que o Fies, que até 2010 havia formalizado pouco mais de 500 mil contratos, tinha condições de garantir até 200 mil novos pedidos, e, inclusive, aportar mais recursos. No que se refere às políticas de garantia de pagamento, Haddad afirmou que havia a intenção de eliminar essa exigência através da criação de um fundo garantidor, embora não tenha precisado para quando isso seria desenvolvido. Por fim, o ministro profetizou o que confirmaria todas as mudanças que estavam por vir:

Esperamos oferecer uma nova alternativa para quem não se adequa ao perfil dos programas que estão hoje em andamento. Temos um caminho longo a percorrer. $\mathrm{O}$ Brasil precisar chegar a 10 milhões de matrículas no ensino superior para saldar minimamente a dívida que tem com a educação (SANTOS, 2010).

Um movimento fundamental que a Lei supracitada alavancou foi a operação de fato do Fundo de Garantia de Operações de Crédito Educativo (FGEDUC), que seria administrado pelo BB: esse dispositivo financeiro já estava previsto especificamente na Lei $n^{\circ} 12.087$, de 11 de novembro de 2009 (BRASIL, 2009a), que autorizava a União a participar, de acordo com o art. $7^{\circ}$, "no limite global de até $\mathrm{R} \$ 4.000 .000 .000,00$ (quatro bilhões de reais), de fundos que, atendidos os requisitos fixados nesta Lei, tenham por finalidade, alternativa ou cumulativamente" [...] "garantir diretamente o risco em operações de crédito educativo, no âmbito de programas ou instituições oficiais, na forma prevista nos estatutos dos respectivos fundos" (inciso III). Em 11 de julho de 2018, o FGEDUC foi reformulado, passando a chamarse Fundo Garantidor do Fundo de Financiamento Estudantil (FG-Fies), e passou a ser administrado pela CEF (BRASIL, 2018c; CEF, 2020)․

O desdobramento específico da Lei $n^{\circ} 12.087 / 2009$ (2009a), para o tema deste artigo, teria início com a MP $\mathrm{n}^{\circ}$ 501, de 8 de setembro de 2010 (BRASIL, 2010b), convertida na Lei $\mathrm{n}^{\circ}$ 12.385, de 3 de março de 2011 (BRASIL, 2011a). A mudança seria basal para o novo funcionamento do Fies: até então, um dos entraves mais importantes do Programa era a necessidade de fiador para a contratação do fundo junto aos agentes bancários, o que se tornou inócuo a partir da assunção do FGEDUC, que passou a ser um "seguro-fiança" a um público específico, conforme expresso pelo MEC (BRASIL, 2011a):

A criação do Fundo de Garantia de Operações de Crédito Educativo (FGEDUC) é outra novidade. Esse fundo atua como garantia nos contratos de estudantes beneficiários de bolsas parciais do Programa Universidade para Todos (ProUni) matriculados em cursos de licenciatura. O FGEDUC atende também estudantes com renda familiar mensal bruta

3 De acordo com Relatório do Ministério da Fazenda (BRASIL, 2018c, p. 10-11), acerca do FG-Fies: "O FGEDUC tem como limite de alavancagem dez vezes o patrimônio líquido do Fundo e conta com um dispositivo de stop loss, acionado quando as perdas atingem $10 \%$ do valor da carteira segurada. Neste caso, para que o Fundo pudesse continuar a honrar as parcelas vencidas e não pagas, e continuar garantindo novas vagas, eram necessários novos aportes de recursos do Tesouro Nacional no FGEDUC. A fim de cumprir com suas funções, o FGEDUC dispõe de patrimônio com a seguinte composição: (i) integralização de cotas; (ii) Comissão pela Concessão de Garantia (CCG); (iii) remuneração de suas disponibilidades e de seus ativos; (iv) receita da recuperação de créditos das operações; (v) devoluções de garantias honradas; e (vi) outros recursos. A Comissão pela Concessão de Garantia (CCG) - 6,25\% do total garantido pelo FGEDUC -, cabia às Mantenedoras e era repassada ao FGEDUC por meio de desconto incidente sobre os encargos educacionais pagos às Mantenedoras referentes aos contratos com cobertura do FGEDUC". 
per capita de até 1,5 salário mínimo. Com o fundo, os estudantes podem contratar o financiamento sem a exigência de fiador.

Esse movimento selaria o futuro da política, permitindo uma expansão nunca dantes vista em uma política de educação superior, na qual o Fundo passaria a ser o "garantidor do risco" de não pagamento. Outra ação criada, que o MEC chamaria de "fiança solidária", permitiu que um grupo de amigos ou familiares ou mesmo colegas do aluno fossem fiadores, mesmo que não tivessem como afiançar bens que cobrissem um possível inadimplemento. Aqui também cabe uma sensível observação no que tange ao FGEDUC: mesmo criado em 2011, só obrigaria as entidades mantenedoras a aderirem ao Fundo como solidárias a partir do despacho da Portaria MEC n 3 , de 13 de janeiro de 2014 (BRASIL, 2014a), ou seja, nesse interstício de três anos, o único risco era do agente operador, o BB e o FNDE.

Estabelecidas as bases de ampliação do Fies, a Portaria MEC $n^{\circ} 1$, de 22 de janeiro de 2010 (BRASIL, 2010d) normatizou o FGEDUC e o modus operandi entre os alunos, as entidades e o operador, consolidando o Novo Fies. Mas não foi apenas a instituição do FGEDUC que repaginou a Política: a partir de 2010, os juros cobrados passaram de $6,5 \%$ anuais para $3,4 \%$, abaixo da inflação naquele ano, que fechou em 5,91\% (IBGE, 2018), facultando, inclusive, a revisão de contratos que estivessem majorados sob a taxa anterior. $O$ SisFies, sistema de inscrição para a concorrência a bolsas, também deixou de operar em períodos específicos e de realizar processos seletivos, permitindo que o interessado solicitasse o financiamento a qualquer tempo. Alunos com bolsas parciais Prouni também poderiam aderir ao Fies como complementação. Além disso, novos ingressantes universitários seriam obrigados a realizar o Exame Nacional do Ensino Médio (Enem) ${ }^{4}$ para aderir ao Programa, mas quem já estivesse cursando poderia pedir o Fies sem cumprir esse requisito.

De volta ao Fies, no que se refere ao prazo de adimplemento da dívida, que até o segundo semestre de 2010 era fixado no dobro do tempo do curso, passou a ser três vezes, somados doze meses após a formatura. Apenas para fins de ilustração, um aluno que tivesse realizado um curso de cinco anos, por exemplo, teria dezesseis anos para quitá-lo. Quanto à carência, definida em 12 meses, passou a ser de 18 meses. Somado a isso, a reformulação facultou a profissionais do magistério público e a médicos vinculados ao Programa Saúde da Família (PSF) o abatimento do saldo devedor na razão de 1\% por mês de trabalho depois de formados (BRASIL, 2011a), sendo ampliado às engenharias nos anos seguintes, o que terminou por tornar o Programa uma espécie de "empréstimo a fundo perdido" para essas categorias (GILIOLI, 2017, p. 201). Outra novidade foi a possibilidade de utilizar débitos para com o Instituto Nacional do Seguro Social (INSS) como crédito ao Fies pelas instituições de ensino, de acordo com a Lei no 12.385, de 3 de março de 2011 (BRASIL, 2011a) (art. 12, Parágrafo Único).

4 O Enem foi instituído através da Portaria $n^{\circ} 438$, de 28 de maio de 1998, com a finalidade de avaliar o desempenho dos estudantes brasileiros quando da conclusão da educação básica, e desde a sua criação já passou por importantes transformações. Desde 1998, quando da sua criação, até aqui, foi ganhando cada vez mais importância, até consolidar-se, a partir de 2009, em função da média obtida, "[...] em referência de autoavaliação e para ingresso ao mundo do trabalho; certificado de conclusão do ensino médio como exame supletivo para maiores de 18 anos; vaga no ensino superior nas instituições que o adotarem no processo seletivo [...]" (PILETTI, 2017, p. 45). Assinala-se que, desde 2017, o Enem não é mais utilizado para certificação do ensino médio. 
Expostas as regras gerais do Novo Fies, a política experimentaria uma verdadeira explosão de inscrições entre 2011 e 2014, passando dos tímidos 71.611 novos contratos em 2010, a 732.494 formalizações, em 2014, somando, até 2020, 3,2 milhões de contratos ativos. Junto a esse crescimento exponencial de adesões, a despesa acompanharia esse impressionante desempenho, de acordo com a Tabela 3:

Tabela 3 - Composição consolidada dos custos Fies - Brasil - 1999-20195

\begin{tabular}{|c|c|c|c|c|c|c|c|c|c|c|c|}
\hline \multirow{3}{*}{$\begin{array}{r}\text { Ano } \\
1999\end{array}$} & \multirow{2}{*}{\multicolumn{2}{|c|}{$\begin{array}{c}\text { Valores } \\
\text { Previstos }\end{array}$}} & \multirow{2}{*}{\multicolumn{2}{|c|}{$\begin{array}{c}\text { Valores } \\
\text { Executados }\end{array}$}} & \multirow{2}{*}{\multicolumn{2}{|c|}{$\begin{array}{l}\text { Subsídio } \\
\text { Implícito }\end{array}$}} & \multirow{2}{*}{\multicolumn{2}{|c|}{$\begin{array}{r}\text { Despesa } \\
\text { FIES/Ano }\end{array}$}} & \multicolumn{3}{|c|}{ Contratos } \\
\hline & & & & & & & & & \multirow{2}{*}{\begin{tabular}{r|} 
Oferecidos \\
-
\end{tabular}} & \multirow{2}{*}{\begin{tabular}{|c|} 
Novos \\
67.202 \\
\end{tabular}} & \multirow{2}{*}{$\begin{array}{c}\text { Ativos } \\
67.202 \\
\end{array}$} \\
\hline & $\mathrm{R} \$$ & 472,23 & $\mathrm{R} \$$ & 472,23 & $\mathrm{R} \$$ & - & $\mathrm{R} \$$ & 472,23 & & & \\
\hline 2000 & $\mathrm{R} \$$ & $1.831,57$ & & $1.311,64$ & $\mathrm{RS}$ & - & $\mathrm{R} \$$ & $1.311,64$ & 100.000 & 35.299 & 102.501 \\
\hline 2001 & $\mathrm{R} \$$ & $1.373,60$ & $\mathrm{R} \$$ & $1.267,35$ & $\mathrm{R} \$$ & - & $\mathrm{R} \$$ & $1.267,35$ & 60.000 & 48.456 & 150.677 \\
\hline 2002 & $\mathrm{R} \$$ & $1.583,72$ & $\mathrm{RS}$ & $1.473,89$ & $\mathrm{R} \$$ & - & $\mathrm{R} \$$ & $1.473,89$ & 80.000 & 65.808 & 218.775 \\
\hline 2003 & $\mathrm{R} \$$ & $1.694,05$ & $\mathrm{R} \$$ & $1.491,05$ & $\mathrm{R} \$$ & 725,90 & $\mathrm{R} \$$ & $2.216,95$ & 70.000 & 49.248 & 271.992 \\
\hline 2004 & $\mathrm{R} \$$ & $1.933,35$ & $\mathrm{R} \$$ & $1.340,14$ & $\mathrm{R} \$$ & 471,49 & $\mathrm{R} \$$ & $1.811,64$ & 50.000 & 42.216 & 312.027 \\
\hline 2005 & $\mathrm{RS}$ & $2.230,85$ & $\mathrm{R} \$$ & $1.377,24$ & $\mathrm{R} \$$ & 638,76 & $\mathrm{R} \$$ & $2.015,99$ & 100.000 & 77.202 & 372.038 \\
\hline 2006 & $\mathrm{RS}$ & $1.678,80$ & $\mathrm{RS}$ & $1.620,08$ & $\mathrm{R} \$$ & 318,97 & $\mathrm{R} \$$ & $1.939,05$ & 100.000 & 58.259 & 377.662 \\
\hline 2007 & $\mathrm{R} \$$ & $1.909,34$ & $\mathrm{R} \$$ & $1.508,76$ & $\mathrm{R} \$$ & 593,57 & $\mathrm{R} \$$ & $2.102,33$ & 100.000 & 47.900 & 425.001 \\
\hline 2008 & $\mathrm{RS}$ & $2.095,03$ & $\mathrm{RS}$ & $1.632,81$ & $\mathrm{R} \$$ & $3.201,11$ & $\mathrm{R} \$$ & $4.833,92$ & 100.000 & 32.384 & 473.340 \\
\hline 2009 & $\mathrm{RS}$ & $2.445,78$ & $\mathrm{R} \$$ & $1.721,30$ & $\mathrm{R} \$$ & $1.038,57$ & $\mathrm{R} \$$ & $2.759,86$ & 100.000 & 32.781 & 486.718 \\
\hline 2010 & $\mathrm{RS}$ & $2.871,66$ & $\mathrm{R} \$$ & 514,29 & $\mathrm{R} \$$ & $1.641,86$ & $\mathrm{R} \$$ & $2.156,16$ & 200.000 & 76.133 & 529.553 \\
\hline 2011 & $\mathrm{R} \$$ & $2.795,72$ & $\mathrm{R} \$$ & $2.185,07$ & $\mathrm{R} \$$ & 25,15 & $\mathrm{R} \$$ & $2.210,23$ & 415.000 & 154.222 & 583.757 \\
\hline 2012 & $\mathrm{R} \$$ & $3.401,75$ & $\mathrm{R} \$$ & $6.163,70$ & $\mathrm{RS}$ & 768,13 & $\mathrm{R} \$$ & $6.931,84$ & 502.500 & 377.899 & 918.137 \\
\hline 2013 & $\mathrm{R} \$$ & $2.483,00$ & $\mathrm{R} \$$ & $11.631,31$ & $\mathrm{R} \$$ & 823,77 & $\mathrm{R} \$$ & $12.455,08$ & 875.000 & 559.910 & 1.168 .100 \\
\hline 2014 & $\mathrm{R} \$$ & $2.159,17$ & $\mathrm{R} \$$ & $20.224,50$ & $\mathrm{R} \$$ & $2.410,94$ & $\mathrm{R} \$$ & $22.635,44$ & 600.512 & 732.686 & 1.910 .718 \\
\hline 2015 & $\mathrm{RS}$ & $14.898,74$ & $\mathrm{R} \$$ & $17.534,32$ & $\mathrm{R} \$$ & $7.881,25$ & $\mathrm{R} \$$ & $25.415,57$ & 313.947 & 287.477 & 2.185 .038 \\
\hline 2016 & $\mathrm{RS}$ & $20.870,80$ & $\mathrm{RS}$ & $20.257,94$ & $\mathrm{R} \$$ & $12.739,30$ & $\mathrm{R} \$$ & $32.997,24$ & 325.279 & 203.634 & 2.441 .008 \\
\hline 2017 & $\mathrm{RS}$ & $22.497,28$ & $\mathrm{R} \$$ & $21.779,49$ & $\mathrm{RS}$ & $8.206,77$ & $\mathrm{R} \$$ & $29.986,26$ & 230.364 & 175.946 & 2.765 .439 \\
\hline 2018 & $\mathrm{RS}$ & $18.514,16$ & $\mathrm{RS}$ & $16.819,49$ & $\mathrm{R} \$$ & $4.978,92$ & $\mathrm{R} \$$ & $21.798,41$ & 310.000 & 82.421 & 1.808 .453 \\
\hline 2019 & $\mathrm{RS}$ & $12.398,52$ & $\mathrm{R} \$$ & $8.560,45$ & $\mathrm{R} \$$ & $3.948,00$ & $\mathrm{R} \$$ & $12.508,45$ & 100.000 & 85.037 & \begin{tabular}{|l|}
690.220 \\
\end{tabular} \\
\hline 2020 & $\mathrm{R} \$$ & - & $\mathrm{R} \$$ & - & $\mathrm{R} \$$ & $4.041,00$ & $\mathrm{R} \$$ & $4.041,00$ & 100.000 & & \\
\hline 2021 & $\mathrm{R} \$$ & - & $\mathrm{R} \$$ & - & $\mathrm{R} \$$ & $5.195,00$ & $\mathrm{R} \$$ & $5.195,00$ & 54.000 & & \\
\hline 2022 & $\mathrm{R} \$$ & - & $\mathrm{R} \$$ & - & $\mathrm{RS}$ & $6.868,00$ & $\mathrm{R} \$$ & $6.868,00$ & 54.000 & & \\
\hline
\end{tabular}

Fonte: Elaborada pelos autores (2020). Vide Nota ${ }^{6}$.

A partir do segundo semestre de 2014, o País passou a enfrentar importante retração econômica e, no início de 2015, o Fies não ficou alheio a isso, mas o que terminaria por eclipsar sua evolução foi a combinação de uma crise econômica que se aproximava e uma matemática que não fechava: embora os investimentos com o Fies subissem exponencialmente, a profecia de Haddad não se confirmava, quer seja, o cabalístico número de 10 milhões de universitários. Novos contratos eram assinados, mas matrículas seguiam seu crescimento quase vegetativo.

Se, em 2010, o Fies financiava $13,3 \%$ das matrículas ativas na educação superior presencial, em 2016 esse percentual era de 52,1\%. É nesse ponto que a matemática parece não fechar - como o Fies pode ter multiplicado seu número de contratos em 409,86\% entre 2010 e 2017, mas as matrículas privadas evoluíram apenas $17,54 \%$ no mesmo período?

5 Em milhões, em valores atualizados pelo IPCA-A de dez. 2019. Disponível em: https://www.ibge.gov.br/estatisticas/economicas/precos-e-custos/9256-indice-nacional-de-precos-ao-consumidoramplo.html?=\&t=series-historicas. Acesso em 15 fev. 2020.

6 Valores previstos e valores executados: 1999: (BRASIL, 1999e); 2000 a 2004 (BRASIL; CEF, 2000; 2001; 2002; CEF, 2003; 2004); 2005 a 2019 (BRASIL, 2020a). Subsídio implícito: 2003 a 2018 (BRASIL, 2020b); 2020 a 2022 (FNDE, 2019a). 
Análise das Relações entre os Setores Público e Privado na Educação Superior no Âmbito do Fies

Tamanha distorção, que já era percebida, passou a ser escrutinada pela academia, pela mídia e por órgãos de controle a partir do segundo semestre de 2014.

Tantas análises, realizadas por tantos grupos, de tantos órgãos, resultaram na MP $\mathrm{n}^{\circ}$ 785, de 6 de julho de 2017 (BRASIL, 2017a), convertida em Lei ${ }^{\circ}$ 13.530, de 7 de dezembro do mesmo ano (BRASIL, 2017b), após mais de 300 emendas ao texto original, que terminaria por reconfigurar o Fies novamente.

As próximas análises contarão com gráficos como recursos de apoio, a partir dos resultados consolidados na Erro! Fonte de referência não encontrada.. O Erro! Fonte de referência não encontrada. e o Erro! Fonte de referência não encontrada. detalham o crescimento das matrículas brasileiras, em números e respectivos percentuais.

Gráfico 1 - Matrículas totais - Brasil: públicas e privadas (1999-2018)

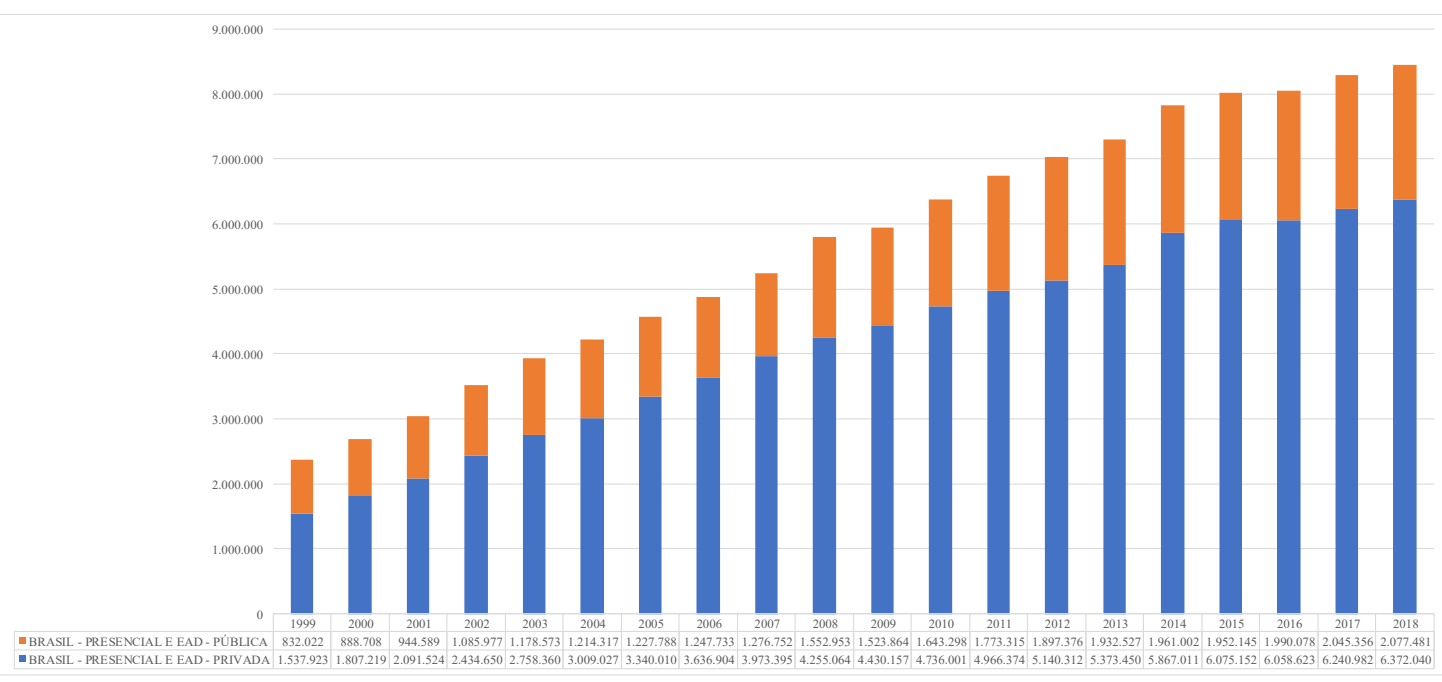

Fonte: Elaborado pelos autores (2020).

Gráfico 2 - Matrículas percentuais - Brasil: públicas e privadas (1999-2018)

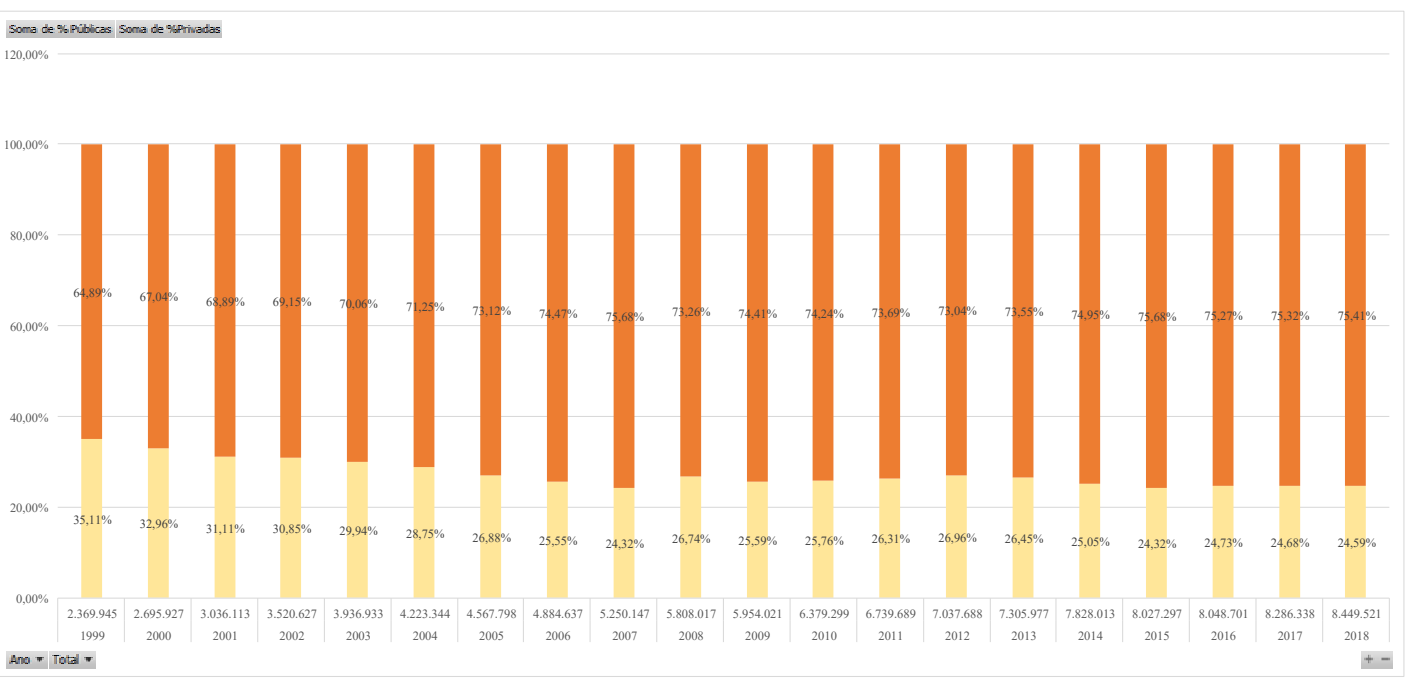

Fonte: Elaborado pelos autores (2020).

A partir do Erro! Fonte de referência não encontrada.1 e do Erro! Fonte de referência não encontrada.2, é possível visualizar com mais clareza a constante ocupação das matrículas privadas, presenciais e EAD. Se, em 1999, essa diferença era de pouco mais 
de dois para um, desde 2005 mantém uma constante de três para um. Essa projeção também se confirma pela importante ocupação da EAD das instituições privadas, que experimentou projeção de mais de $1.000 \%$ no período analisado.

O Erro! Fonte de referência não encontrada.3 e o Erro! Fonte de referência não encontrada.4 expõem um comparativo entre as matrículas brasileiras frente ao Prouni, ao Fies e às matrículas privadas presenciais no período. O Prouni, como destacado anteriormente, também consiste em uma importante política educacional de expansão do acesso à educação superior.

Gráfico 3 - Matrículas Brasil (pública e privada, presencial e EAD), Fies e Prouni (1999-2018)

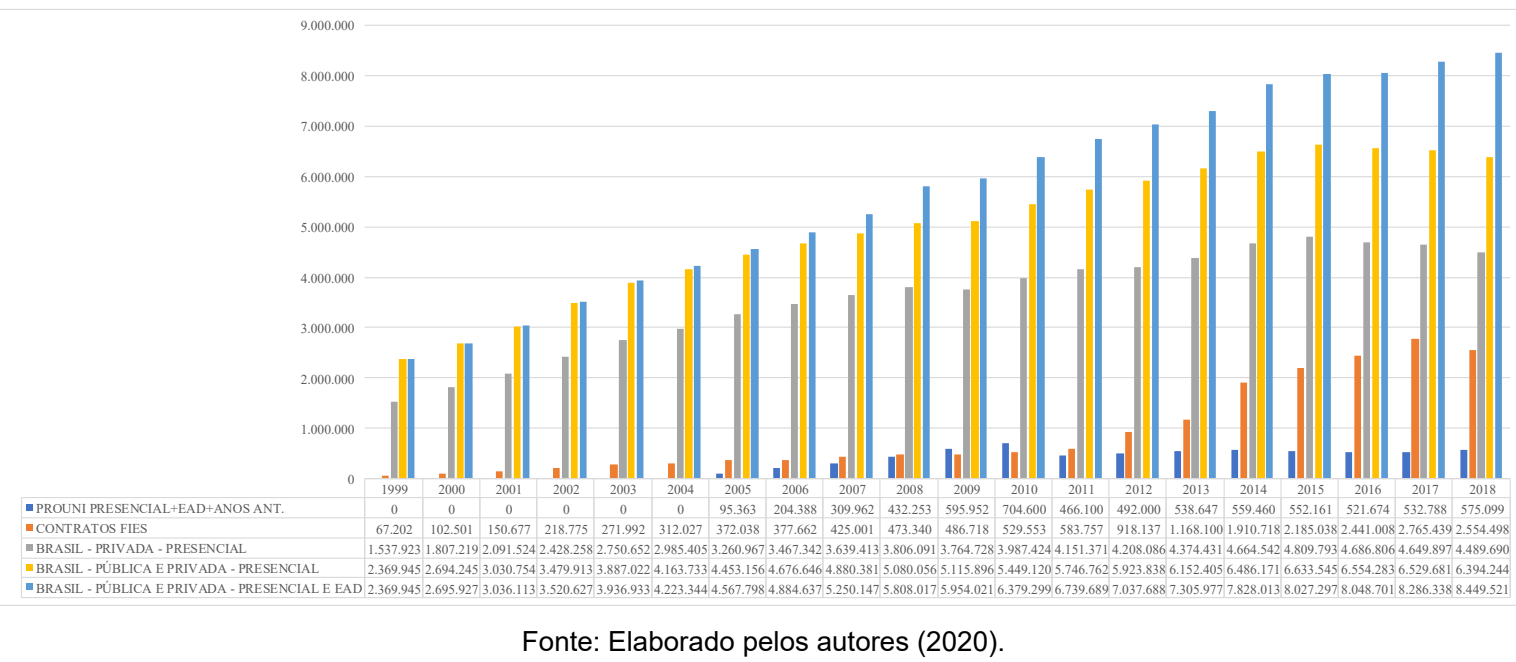

Gráfico 4 - Matrículas Brasil (pública e privada, presencial e EAD), Fies e Prouni (2011-2018)

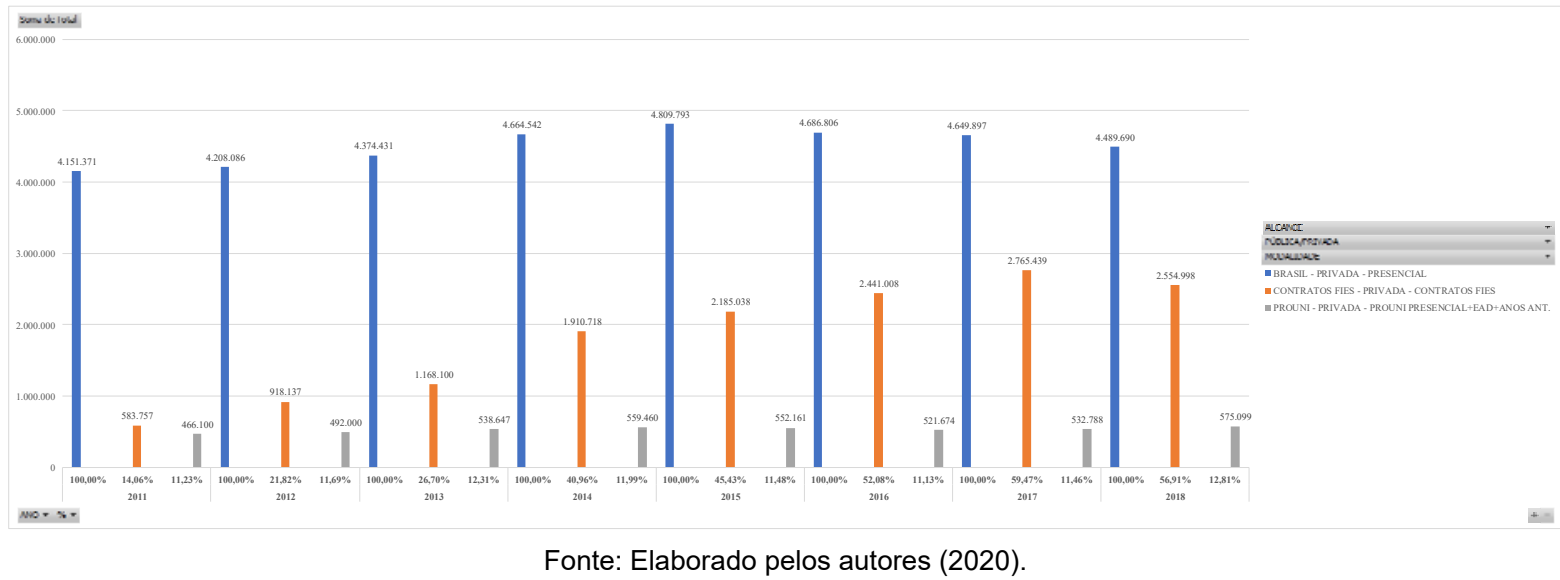

De acordo com o Erro! Fonte de referência não encontrada.3 e o Erro! Fonte de referência não encontrada.4, se em 2005 as políticas Fies e Prouni compunham 11,4\% das matrículas em instituições privadas presenciais, em 2017 esse total disparou: 70,9\% de todos os estudantes vinculados a cursos de graduação presencial tinham algum desses incentivos. Nesse recorte, $59,4 \%$ eram contratantes do Fies e $11,46 \%$ beneficiários Prouni, ante os 4.649.897 alunos matriculados.

Quando analisados os microdados do Fies, foi possível chegar a novas combinações possíveis, para o intervalo 2011 até 2019 , esboçando um perfil detalhado dos contratantes: raça/cor branca; sexo feminino; faixa etária entre 19 e 24 anos de idade. Combinado aos 
Análise das Relações entre os Setores Público e Privado na Educação Superior no Âmbito do Fies

dados anteriores, identifica-se também que residem na região Sudeste; não são integrantes do público-alvo da educação especial; são procedentes de escola pública; optantes por um curso de bacharelado; financiaram $100 \%$ do curso realizado, e, quando não conseguiram financiamento total, também não utilizaram o Prouni; procuraram a Caixa Econômica Federal para conduzir seu contrato e utilizaram o fundo garantidor do próprio Fies, FGEDUC/FG-Fies, para garantir o pagamento do seu curso. Seguindo a tendência dos demais estudantes de ensino médio brasileiros, $73,1 \%$ dos estudantes Fies vêm de escola pública, o que confirma a importância do programa para o acesso à educação superior. Nesse aspecto, o Fies guarda importante relação com uma política de diminuição da desigualdade social. Tais percentuais podem ser observados no Gráfico 5:

\section{Gráfico 5 - Síntese das características predominantes dos estudantes Fies, a partir dos} microdados Fies 2011-2019

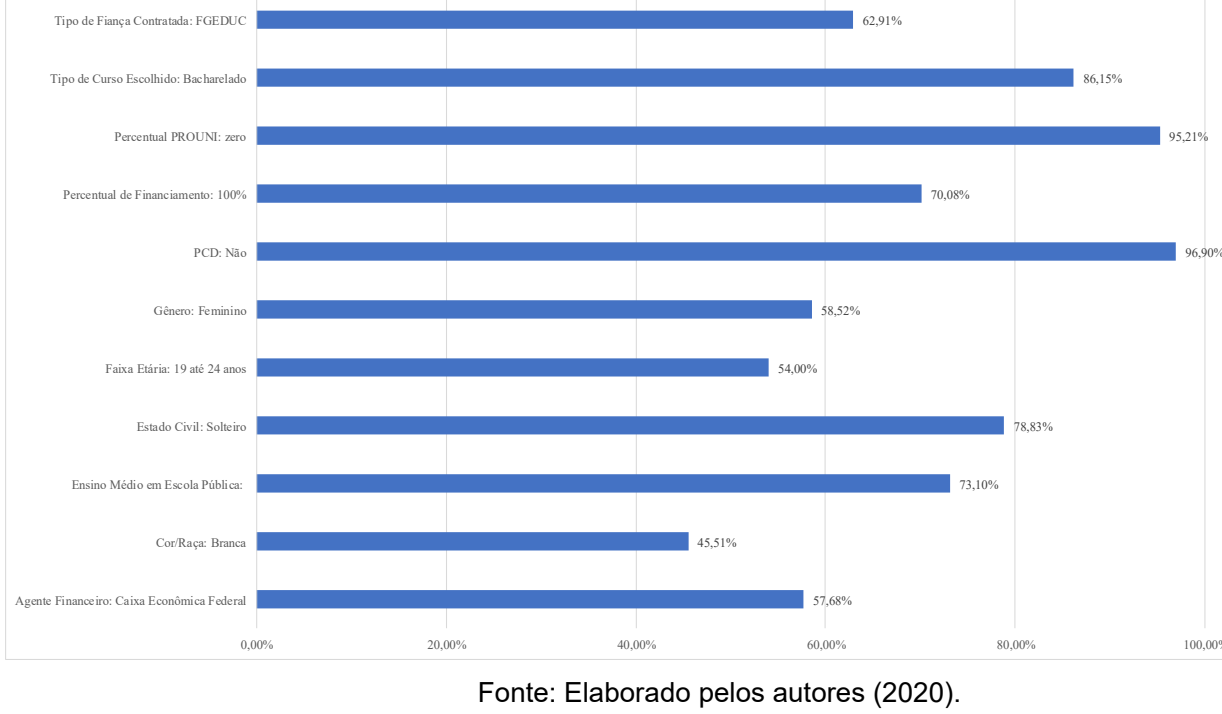

Ao analisar os números do Fies, em face à educação superior no período em tela, é evidente a importância que o Fundo teve na expansão das matrículas. Além disso, o Fies, sob esse viés, permite três olhares distintos: o primeiro, social, ao observar os estudantes sob o ângulo do direito à educação; o segundo, econômico, quando se estuda o impacto da educação superior nos números dos orçamentos público e privado; e um terceiro olhar, político, pois se trata de uma política pública de importante disputa no setor educacional.

\section{Para finalizar}

Entendida com um discurso palatável e justificável, a tese do ensino público pago, no caso da universidade, deve ser vista com muita atenção.

O Fies, criado em 1999 como um desdobramento do Programa Crédito Educativo, de 1975, já atingiu 3,2 milhões de estudantes. Destes, 2,72 milhões entre 2010 e 2019, anos em que as análises sociais e educacionais foram aqui focadas. Contudo, sua imbricada relação entre os setores público e privado permitiu concluir que, em primeira instância, o Fies não é uma política genuinamente brasileira, uma vez que já é praticada em diversos países pelo mundo, a exemplo da Austrália, da Alemanha e dos Estados Unidos, salvaguardadas suas características locais, mas o enriquecimento de instituições de ensino é um ponto marcante aqui. 
Embora tenha registrado números tímidos até 2009, o Fies passou por importantes reformulações em 2010, através do Novo Fies, que ensejaram o interesse de grande número de estudantes do ensino médio a contrair o financiamento, além de estudantes que já cursavam o ensino superior privado, mas pagavam o curso integralmente. As reformulações de 2010 permitiram o acesso a praticamente $50 \%$ dos estudantes financiados, apenas entre 2013 e 2014, considerados os anos mais vigorosos da política.

Em 2015 o Fies sofreu importante revés, em função de acontecimentos econômicos e políticos de âmbito nacional que eclipsaram a política em tela e mantiveram outras políticas educacionais estagnadas, como o Prouni, que seguiu constante, mas sem avanços.

Em 2017, após intensa análise e investigação da mídia, da academia, do Ministério da Fazenda e do Tribunal de Contas da União, o Fies foi reformulado novamente, quando foi criado o Novo Fies, que pode ser chamado de "Novo Fies 2", para fins de distinção com a reformulação realizada em 2010.

Além das alterações realizadas no Fies em torno da linha de corte para obtenção do Fies ou P-Fies, cumpre destacar ainda ser positiva a maior participação em cursos prioritários, como formações em áreas da educação e da saúde, além da priorização de cursos avaliados com notas 4 ou 5 no Sinaes. Outro ponto positivo refere-se à priorização regional, com atenção às regiões Norte, Nordeste e Centro-Oeste, excluído o Distrito Federal. A questão da nota de corte do Enem pode ser vista como controversa: se, por um lado, parece uma garantia mínima de conclusão do curso, pois se habilitam ao financiamento estudantes com demonstração de desempenho considerado razoável, por outro lado parece mais um ferrolho na garantia ao direito universal à educação.

Em segunda instância, a análise do Fies induz à conclusão de que a política foi fundamental para a expansão do acesso à educação superior. Contudo, perdeu-se o fio condutor no interstício entre o primeiro semestre de 2011 e o segundo semestre de 2014, quando os alunos matriculados convertiam seu modo de pagamento para o financiamento subsidiado, sem qualquer controle no período, promovendo o enriquecimento a fundo certo para algumas instituições e o endividamento dos estudantes, além de um crescimento vegetativo do acesso dos estudantes, o que não se revelava como objetivo central do Novo Fies. Ainda assim, se bem triangulado, o Fies revela-se como importante mecanismo de acesso à educação terciária, especialmente após as correções realizadas. Infelizmente, desde as mudanças implementadas em 2018, o que se observa é a diminuição do programa, ano a ano, como se as próprias soluções encontradas não dessem conta da manutenção do programa, e todos os próximos estudantes tivessem que pagar pelos erros do passado. Essa diminuição ficou evidente no número de contratos firmados em 2019. Em última instância, destaca-se a aproximação do Fies ao campo público-privado. Campo entendido como teorizado por Pierre Bourdieu, em 1980 e em 1991, e explicado por Bernard Lahire como um "[...] espaço de lutas, uma arena onde está em jogo uma concorrência ou competição entre os agentes que ocupam as diversas posições" (LAHIRE, 2017, p. 65). Nessa perspectiva, é possível argumentar que o Fies, como programa de inversão financeira mantido pelo Estado, foi e continuará sendo objeto de disputa do "capital específico do campo" (LAHIRE, 2017), quer seja, o orçamento público, procurando, sempre que possível, explicar que a educação superior privada pode coexistir com a educação pública, sem que o Estado deixe de ofertar esse benefício social, seja diretamente, seja através de bolsas ou empréstimos de pagamento futuro. 
Análise das Relações entre os Setores Público e Privado na Educação Superior no Âmbito do Fies

\section{Referências}

ADORNO, Sérgio. Educação e patrimonialismo. Cadernos CEDES, Campinas, n. 25, p. 9-27, 1991.

BRASIL. Ministério da Educação. Portaria n 438, de 28 de maio de 1998. Brasília, DF, 1998. BRASIL. Medida Provisória n 1.827 , de 27 de maio de 1999. Diário Oficial da União, Brasília, DF, 1999a.

BRASIL. Medida Provisória n 1.865-2, de 29 de Junho de 1999. Diário Oficial da União, Brasília, DF, 1999b.

BRASIL. Medida Provisória n 1.972-8, de 10 de dezembro de 1999. Diário Oficial da União, Brasília, DF, 1999c.

BRASIL. Banco Central. Resolução n 2.647, de 22 de setembro de 1999. Brasília, 1999d. BRASIL. Câmara dos Deputados. Fies: Valores previstos e executados - 1999. Sistema de execução da LOA - 1995 a 2001. Brasília, DF, 1999e.

BRASIL. Ministério da Educação. Portaria $n^{\circ}$ 860, de 27 de maio de 1999. Brasília, DF, 1999f.

BRASIL. Ministério da Educação. Portaria n 1.386, de 15 de setembro de 1999. Brasília, DF, 1999g.

BRASIL. Ministério da Educação; CEF. Fies: Relatórios de gestão dos exercícios de 1999, 2000, 2001 e 2002. Brasília, DF, 1999h; 2000; 2001; 2002.

BRASIL. Medida Provisória n 2.094-22, de 27 de dezembro de 2000. Diário Oficial da União, Brasília, DF, 2000.

BRASIL. Lei no 10.260, de 12 de julho de 2001. Diário Oficial da União, Brasília, DF, 2001. BRASIL. Ministério da Educação. Fies: Relatórios de gestão dos exercícios de 2008 a 2017. Brasília, DF, 2008; 2009b; 2010c; 2011b; 2012; 2013; 2014b; 2015; 2016; 2017c.

BRASIL. Lei $n^{\circ}$ 12.087, de 11 de novembro de 2009. Diário Oficial da União, Brasília, DF, 2009a.

BRASIL. Lei n 12.202, de 14 de janeiro de 2010. Diário Oficial da União, Brasília, DF, 2010a.

BRASIL. Medida Provisória n 501, de 8 de setembro de 2010. Diário Oficial da União, Brasília, DF, 2010b.

BRASIL. Secretaria de Educação Superior. Portaria Normativa $n^{\circ} 1$, de 22 de janeiro de 2010. Brasília, DF, 2010d.

BRASIL. Lei n 12.385, de 3 de março de 2011. Diário Oficial da União, Brasília, DF, 2011a.

BRASIL. Ministério da Educação. Portaria Normativa $n^{\circ}$ 3, de 13 de janeiro de 2014. Brasília, DF, 2014a.

BRASIL. Medida Provisória n 785, de 6 de julho de 2017. Diário Oficial da União, Brasília, DF, 2017a. 
Análise das Relações entre os Setores Público e Privado na Educação Superior no Âmbito do Fies

BRASIL. Lei $n^{\circ}$ 13.530, de 7 de dezembro de 2017. Diário Oficial da União, Brasília, DF, 2017b.

BRASIL. Decreto n 9.292, de 23 de fevereiro de 2018. Diário Oficial da União, Brasília, DF, 2018a.

BRASIL. Ministério da Educação. Portaria nº 209, de 7 de março de 2018. Brasília, DF, 2018b.

BRASIL. Ministério da Fazenda. Avaliação do Fundo de Financiamento Estudantil - Fies. Brasília, DF, 2018c.

BRASIL. Senado Federal. SIGA Brasil - Painel especialista do Senado. Brasília, DF, 2020a.

BRASIL. Ministério da Economia. Relatório de benefícios tributários, financeiros e creditícios no período de 2003 a 2018. Brasília, DF, 2020b.

CEF. Caixa Econômica Federal. Fies: Relatórios de gestão dos exercícios de 2000, 2003, 2004, 2005, 2006 e 2007. Brasília, DF, 2000; 2003; 2004; 2005; 2006; 2007.

CEF. Caixa Econômica Federal. Fundo Garantidor do Fundo de Financiamento Estudantil - FG-Fies. Brasília, DF, 2020.

CRESWELL, John W. Projeto de pesquisa: métodos qualitativo, quantitativo e misto. Porto Alegre: Artmed, 2010.

FNDE. Fundo Nacional de Desenvolvimento da Educação. Microdados: Fies - 2011/1 até 2019/2. Brasília, DF, 2011a; 2011b; 2012a; 2012b; 2013a; 2013b; 2014a; 2014b; 2015a; 2015b; 2016a; 2016b; 2017a; 2017b; 2018b; 2018c; 2019b; 2019c.

FNDE. Fundo Nacional de Desenvolvimento da Educação. Fies: Repasse de CFT-E. Brasília, DF, 2018a.

FNDE. Fundo Nacional de Desenvolvimento da Educação. Estudantes inadimplentes poderão renegociar as dívidas com o Fies a partir do segundo semestre. Brasília, DF, 2018d. Disponível em: http://www.fnde.gov.br/acesso-a-informacao/institucional/area-deimprensa/noticias/item/11952-estudantes-inadimplentes-poderão-renegociar-as-dívidascom-o-fies-a-partir-do-segundo-semestre. Acesso em: 13 mar. 2019.

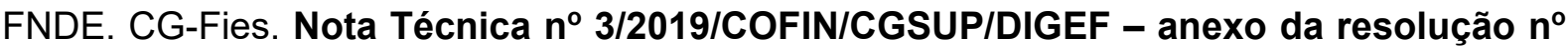
37, de 18 de dezembro de 2019 - Plano Trienal e quantidade de vagas. Brasília, DF, 2019a.

GILIOLI, Renato de Sousa Porto. Um balanço do FIES: desafios, perspectivas e metas do PNE. In: GOMES, Ana Valeska Amaral (Ed.). Plano Nacional de Educação: olhares sobre o andamento das metas. Brasília: Câmara dos Deputados, 2017. p. 195-226.

IBGE. Instituto Brasileiro de Geografia e Estatística. Séries históricas: IPCA e INPC. Rio de Janeiro, 2018.

INEP. Instituto Nacional de Estudos e Pesquisas Educacionais Anísio Teixeira. Evolução do ensino superior - graduação 1980-1998. Brasília, 1998. Disponível em: http://download. inep.gov.br/download/censo/1998/superior/evolucao_1980-1998.pdf. Acesso em: 13 mar. 2019. 
INEP. Instituto Nacional de Estudos e Pesquisas Educacionais Anísio Teixeira. Microdados: Censo da educação superior - 1999 (a) (b). Brasília, DF, 1999a; 1999b.

INEP. Instituto Nacional de Estudos e Pesquisas Educacionais Anísio Teixeira. Microdados: Censo da educação superior - 2000 a 2018. Brasília, DF, 2000b; 2001; 2002; 2003; 2004; 2005; 2006; 2008; 2009; 2010; 2011; 2012; 2013; 2014; 2015; 2016; 2017; 2018; 2019.

LAHIRE, Bernard. Campo. In: CATANI, Afrânio Mendes (Ed.). Vocabulário Bourdieu. Belo Horizonte: Autêntica, 2017. p. 64-66.

LIMA, Kátia. Contra-reforma na educação superior: de FHC a Lula. 1. ed. São Paulo: Xamã, 2007.

MENDES, Marcos José. Por que o Brasil cresce pouco?: desigualdade, democracia e baixo crescimento no país do futuro. Rio de Janeiro: Elsevier, 2014.

MINTO, Lalo Watanabe. As reformas do ensino superior no Brasil: o público e o privado em questão. Campinas: Autores Associados, 2006.

MIZNE, Oliver. A educação como negócio. In: COLOMBO, Sônia Simões (Ed.). Gestão Educacional: uma nova visão. 1. ed. Porto Alegre: Artmed, 2004. p. 125-152.

MORSE, J. M. Approaches to qualitative-quantitative methodological triangulation. Nursing Research, v. 40, n. 2, p. 120-123, 1991. Disponível em: http://ukpmc.ac.uk/abstract/ MED/2003072. Acesso em: 15 jul. 2018.

PILETTI, Nelson. Educação. In: PINSKI, Jaime; MARTINS, José de Souza (Ed.). O Brasil no contexto: 1987-2017. São Paulo: Contexto, 2017. p. 39-54.

SAMPAIO, Helena Maria Sant'Ana. Privatização do ensino superior no Brasil: velhas e novas questões. In: SCHWARTZMAN, Simon (Ed.). A educação superior na América Latina e os desafios do século XXI. Campinas: Unicamp, 2014. p. 139-192.

SANTOS, Débora. Novo Fies terá parcelas fixas até o final do financiamento, diz Haddad. G1, Educação. São Paulo, Educação, p. 1, 2010. Disponível em: http://g1.globo.com/educacao/ noticia/2010/05/novo-fies-tera-parcelas-fixas-ate-o-final-do-financiamento-diz-haddad.html.

Acesso em: 9 jul. 2018.

UNESCO. Organização das Nações Unidas para a Educação a Ciência e a Cultura. Relatório sintético sobre as tendências e desenvolvimentos na educação superior desde a conferência mundial sobre a educação superior. In: UNESCO. Organização das Nações Unidas para a Educação a Ciência e a Cultura; BRASIL. Secretaria de Educação Superior (Ed.). Educação superior: reforma, mudança e internacionalização. Brasília: UNESCO, 2003. p. 93-150.

WORLD BANK. La Enseñanza Superior: las lecciones derivadas de la experiencia. Whashington D.C. 1995. Disponível em: http://documentos.bancomundial.org/curated/ es/274211468321262162/pdf/133500PAPER0Sp1rior0Box2150A1995001.pdf. Acesso em: 8 jul. 2020

WORLD BANK. O Estado num mundo em transformação. Whashington D.C. 1997. Disponível em: http://documents1.worldbank.org/curated/en/634101468162557539/pdf/ 341310PORTUGUE18213137771701PUBLIC1.pdf. Acesso em: 8 jul. 2020. 
Análise das Relações entre os Setores Público e Privado na Educação Superior no Âmbito do Fies

Rodrigo Meleu das Neves é Analista de Tecnologia de Informação do CPD/UFRGS. Doutor em Educação pela Faculdade de Educação da Universidade Federal do Rio Grande do Sul (FACED/UFRGS).

ORCID: http://orcid.org/0000-0002-8587-4481

E-mail: rodrigon@cpd.ufrgs.br

Denise Lindstrom Bandeira é Professora Associada do Departamento de Ciências Econômicas da Escola de Administração da Universidade Federal do Rio Grande do Sul (UFRGS).

ORCID: https://orcid.org/0000-0003-3161-2985

E-mail: deniselb@ea.ufrgs.br 